\title{
Assessment of Unavoidable Corrosive Substance Ingestion in Children
}

\author{
Onur Yalçın ${ }^{1}$, Ali Aygün ${ }^{2}$ \\ ${ }^{1}$ Ordu University, Faculty of Medicine, Department of Pediatric Surgery, Ordu, Turkey \\ ${ }^{2}$ Ordu University, Faculty of Medicine, Department of Emergency Medicine, Ordu, Turkey \\ Received: 13 Februvary 2019, Accepted 18 March 2019, Published online: 28 April 2019 \\ (C) Ordu University Institute of Health Sciences, Turkey, 2019
}

\begin{abstract}
Objective: Corrosive substances are agents which ease our lives, but they can also make children's' lives completely difficult as a result of contact with gastrointestinal tract, respiratory tract and skin. Examinations and treatments of patients hospitalized in our clinic with the complaint of corrosive substance ingestion were examined.

Methods: The records of 45 patients who were hospitalized in our clinic between May 2017 and December 2018 were examined retrospectively. The patients' ages, genders, ingested corrosive substance, admission and discharge inflammatory markers were examined according to diagnosis and treatment type.

Results: Of the 45 cases, 24 (53,3\%) were male, while 21 (46,7\%) were female. The youngest case was 9 months old, the oldest case was 168 months and average age of the cases was 24,7 months. The substances the cases were exposed to were bleacher in 20 patients $(44,4 \%)$, dishwasher detergent in 11 patients $(24,4 \%)$, rinse aid in 5 patients $(11,1 \%)$, drain cleaner in 4 patients $(8,9 \%)$, washing machine detergent in 3 patients $(6,7 \%)$, decalcifier in 1 patient $(2,2 \%)$ and surface cleaner (sodium hypochlorite) in 1 patient $(2,2 \%)$. Endoscopy was performed on two patients with clinical symptoms who ingested drain cleaner. Statistically significant difference was found between the hospitalization and discharge white blood cell count $\times 10^{3} / \mathrm{uL}$ (WBC), lymphocyte count $\times 10^{3} / \mathrm{Ul}$ (LYM), platelet count $\times 10^{3} / \mathrm{uL}$ (PLT), red blood cell width (RDW, \%), mean platelet volume (MPV), neutrophil/lymphocyte ratio (NLR), platelet/lymphocyte ratio (PLR) values of the patients $(\mathrm{p}<0.05)$.

Conclusion: With precautions taken to prevent the ingestion of corrosive substances, a significant cause of morbidity and mortality can be prevented significantly. It is important to raise awareness in families on this issue.
\end{abstract}

Key words: Child, corrosive substances, esophageal stricture

Suggested Citation: Yalçın O, Aygün A. Assessment of Unavoidable Corrosive Substance Ingestion in Children. Middle Black Sea Journal of Health Science, 2019; 5(1): 6-10.

Address for correspondence/reprints:

Onur Yalçın

Telephone number: +90 (452) 2250380

E-mail: onuryalcin@ hotmail.com

DOI: $10.19127 / \mathrm{mbsjohs} .526836$

\section{Introduction}

Chemical substances which are used in every area of our lives both increase the quality of life and also cause a serious risk. Accidental or deliberate ingestion of these by children cause unavoidable caustic intoxications. Due to reasons such as putting corrosive substances in colorful containers that can attract children's interest, in food and drink boxes and in places where children can easily reach, ingestion of corrosive substances is one of the most important and most frequent home accidents in childhood (Ashcraft and Padula, 1974). In the United States, more than ten thousand new cases are recorded annually. Although there is no specified 
figure in Turkey, it is around 3-5 thousand annually (Sumeli, 2018).

Especially small children constitute the risky group because of their extreme interest in the environment and putting everything they find into their mouths. Corrosive substances are substances which give both histological and functional damage when they contact the mucosa (Rama and Robert, 1998). Corrosive substances can have alkali or acid properties. Irrespective of their being acid or alkali, these substances may not cause any harm depending on the amount they are ingested, their type or being in liquid or solid form; however, they can also frequently cause severe burnt that can be seen on the mouth and esophagus and even serious complications that can result in death. Corrosive esophagitis frequently occurs with alkali type agents. While all acids except hydrochloric acid cause coagulation necrosis, alkali agents cause liquefaction necrosis. The damage caused by alkalis can reach the depths of tissue (Berthet et al., 1994; Hugh and Kelly 1999). Acids cause superficial burnt, since they neutralize with saliva, they show less effect on esophagus; however, their passage is fast since their viscosity is low. They quickly transfer to the stomach and they can cause burnt in all parts of the stomach, especially the antrum and pylorus, by combining with stomach acids (Nicosia et al., 1974; Jelenko et al., 1974).

In this study, we planned to assess the frequency of contacted corrosive substances, clinical findings, changes in inflammatory markers, diagnosis and treatment phases of patients who referred to the emergency service of our hospital and who were hospitalized by our service due to corrosive substance contact, which does not have a standard treatment protocol yet.

\section{Methods}

Ordu Provincial Health Directorate and Ordu University Medical Faculty Training and Research Hospital Clinical Practice Ethics Committee approvals were obtained (Date:07/02/2019, Number: 2019-23). All pediatric patients who were hospitalized in the pediatric surgery clinic of tertiary training and research hospital between May 2017 and December 2018 were included in the study. File records of a total of 45 patients were examined retrospectively in terms of gender, referral age, complete blood count device (ABX Pentra DX 120) was used for the measurement of blood parameters. White blood cell count $\times 10^{3} / \mathrm{uL}$ (WBC), lymphocyte count $\times 10^{3} / \mathrm{uL} \quad(\mathrm{LYM})$, neutrophil count $\times 10^{3} / \mathrm{uL}$ (NEU), platelet count $\times 10^{3} / \mathrm{uL}$ (PLT), mean platelet volume fL (MPV), red blood cell width (RDW,\%), platelet distribution width $\mathrm{fL}$ (PDW), platelet /lymphocyte ratio (PLR), neutrophil / lymphocyte ratio (NLR), platelet/neutrophil ratio (PNR), platelet distribution width/red blood cell width ratio (PDW / RDW), C-reactive protein (CRP), biochemical blood tests, physical examination finding records, chest radiography, direct abdominal X-ray, treatment given during hospitalization period, total period of hospitalization, type of corrosive substances ingested, findings and surgery requirements. The cases whose files were found to be incomplete were excluded from the study. Oral intake of patients who had burnt was stopped for 48-72 hours and they were started maintenance fluid therapy, antibiotherapy and $\mathrm{H} 2$ receptor antagonist, and those with clinical symptoms were started intravenous steroid. The patients whose lesions regressed and who were able to ingest fluid food were discharged with esophagography planned for three weeks later. The cases were assessed in terms of age, gender, the quality of the ingested substance, examination results and treatment. A statistical package program was used for statistical analysis. Descriptive analysis of assessment results was given as numbers and percentage for categorical variables and as mean, standard deviation, minimum and maximum for numerical variables. Kolmogorov Smirnov test was used to test normality distribution. Paired t test was used in normally distributed parameters for intergroup comparisons, while Wilcoxon test was used for parameters which were not normally distributed. Statistical alpha significance level was accepted as $\mathrm{p}<0,05$.

\section{Results}

Of the 45 cases, $24(53,3 \%)$ were male, while 21 $(46,7 \%)$ were female. The youngest case was 9 months old, the oldest case was 168 months and average age of the cases was 24,7 months. The substances the cases were exposed to were bleacher in 20 patients $(44,4 \%)$, dishwasher detergent in 11 patients $(24,4 \%)$, rinse aid in 5 patients $(11,1 \%)$, drain cleaner in 4 patients $(8,9 \%)$, washing machine detergent in 3 patients $(6,7 \%)$, decalcifier in 1 patient $(2,2 \%)$ and surface cleaner (sodium hypochlorite) in 1 patient $(2,2 \%)$, respectively in terms of frequency (Graphic 1). The most frequent referral symptom was edema around the mouth. $2(4,4 \%)$ of the patients were found to have chemical burnt on the femur. Two patients who ingested drain cleaner were 


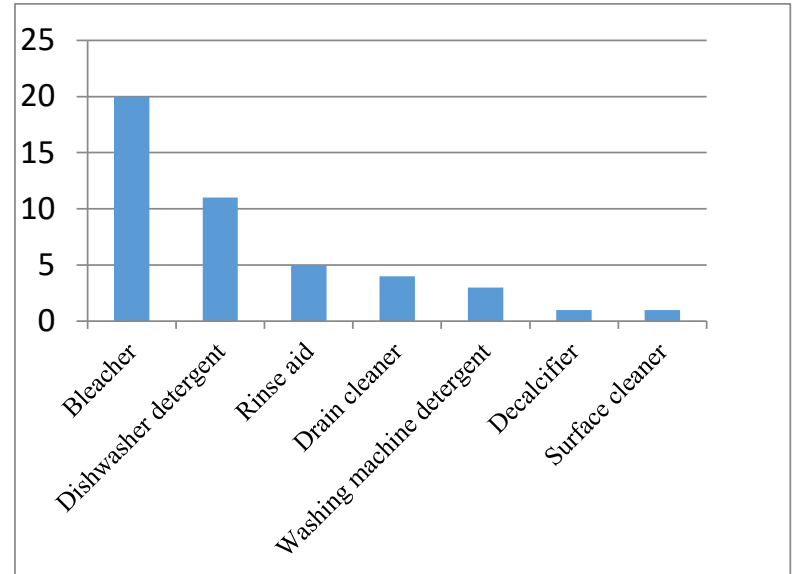

Graphic 1. Corrosive substances contacted

found to have lesion and hypersalivation inside the mouth. Diagnostic esophagoscopy was performed on these patients. Two of the patients were not found to have pathology. In the two patients who had burnt on femur, the burnt was found to recover in 5-7 days without any scars. None of the patients followed were found to have narrowing of the esophagus perforation in their checkups after discharge. No statistically significant difference was found between the hospitalization and discharge NEU, PDW, PNR, PDW/RDW and CRP values of the patients, $(p>0.05)$. Statistically significant difference was found between the hospitalization and discharge WBC, LYM, PLT, RDW, MPV, NLR, PLR values of the patients $(\mathrm{p}<0.05)($ Table 1$)$.

Table 1. Comparison of hospitalization and discharge biomarker averages of patients

\begin{tabular}{lllc}
\hline Parameters & $\begin{array}{c}\text { Hospitalization } \\
(\text { Mean } \pm \text { SD) }\end{array}$ & $\begin{array}{l}\text { Discharge } \\
(\text { Mean } \pm \text { SD) }\end{array}$ & $\begin{array}{c}\text { p } \\
\text { Value }\end{array}$ \\
\hline WBC $\times 10^{3} / \mathrm{uL}$ & $12,09 \pm 3,62$ & $8,21 \pm 2,59$ & $<\mathbf{0 , 0 1}$ \\
\hline $\begin{array}{l}\text { Neutrophil } \\
\text { count } \times 10^{3} / \mathrm{uL}\end{array}$ & $4,04 \pm 1,82$ & $7,58 \pm 2,93$ &, 296 \\
\hline $\begin{array}{l}\text { Lymphocyte } \\
\text { count } \times 10^{3} / \mathrm{uL}\end{array}$ & $6,58 \pm 3,27$ & $3,28 \pm 1,37$ & $<\mathbf{0 , 0 1}$ \\
\hline $\begin{array}{l}\text { Platelet } \\
\text { count } \times 10^{3} / \mathrm{uL}\end{array}$ & $372,23 \pm 118,74$ & $336,46 \pm 103,36$ & $<\mathbf{0 , 0 1}$ \\
\hline RDW,$\%$ & $15,11 \pm 2,18$ & $15,23 \pm 2,21$ & $\mathbf{, 0 0 2}$ \\
\hline MPV fL & $8,8 \pm 1,06$ & $8,93 \pm 1,02$ & $\mathbf{, 0 4 9}$ \\
\hline PDW fL & $9,86 \pm 2,72$ & $10,06 \pm \mathbf{2 , 4 2}$ &, 217 \\
\hline PNR & $114,95 \pm 75,46$ & $91,87 \pm 46,05$ &, 102 \\
\hline NLR & $0,89 \pm 1,01$ & $1,52 \pm 1,34$ & $<\mathbf{0 , 0 1}$ \\
\hline PLR & $92,78 \pm 193,73$ & $114,32 \pm 64,64$ & $<\mathbf{0 , 0 1}$ \\
\hline PDW/RDW & $0,69 \pm 0,16$ & $0,68 \pm 0,16$ &, 376 \\
\hline CRP & $0,15 \pm 0,13$ & $0,16 \pm 0,18$ &, 077 \\
\hline
\end{tabular}

\section{Discussion}

In children, the degree of damage caused by burnt is associated with the type, concentration and amount of the substance ingested, the period of contact and secondary infections that may develop later (Oldham et al., 2005). In the first and second weeks of corrosive substance ingestion, thrombosis in submucosal veins and therefore necrosis and increase in edema are seen. After the third week, with fibroblasts settling in the submucosa, stenosis can occur depending on the degree of fibrosis and damage. Stenosis, which is the feared complication in clinic, can occur in $25-50 \%$ of the cases. While the use of medical treatment is disputed today, the basis of treatment is the prevention of inflammatory reaction and stenosis (Ashcraft and Padula, 1974; Kasap and Ozutemiz, 2006).

Typical symptoms following corrosive substance ingestion are salivating from the side of the mouth, edema on the lips, burnt induced lesions around or inside the mouth, dyspnea, stridor, tachypnea, tachycardia, hoarseness and abdominal pain. Although these symptoms bring burnt into mind, they do not always mean that burnt is present. On the other hand, absence of these symptoms does not eliminate esophagus burnt (Cankorkmaz, 2009). In patients with corrosive substance ingestion, first cessation of oral feeding, intravenous fluid treatment and antibiotherapy are mostly accepted treatment approaches in the acute phase. The primary complication that can be seen in patients after the acute phase is esophageal stenosis (Oldham et al., 2005).

Steroid therapy in corrosive esophagitis is a disputed topic. Although it is reported in some studies that steroid therapy decreases the development of stenosis significantly, some other studies report that steroid is not useful in preventing stenosis and it can even cover mediastinitis clinic in patients with a high risk of perforation (Hawkins et al., 1980; Anderson et al., 1990; Fulton and Hoffman, 2007). In our study, we started intravenous steroid therapy in patients with symptoms. Corrosive substance use was most seen in pre-school children and boys. These results are in parallel with the literature (Kayaalp et al., 2006). Corrosive substance ingestion is seen to peak in two age groups. The first one is 0-5 age group in which children have too much curiosity and wish to learn, take everything into their mouths and imitate elders; while the second one is adolescence period for suicidal purposes (Wasserman and Ginsburg, 1985; Aksu and İnan, 2002). In parallel with the literature, the most frequently ingested substance is hypochloric acid (bleacher) in our study with a rate of $44,4 \%$ (Atabek et al., 2007). Complications related with corrosive substance ingestion were not seen in any of our patients who ingested bleacher and who were followed only with medical monitoring. In literature inflammatory markers are examined in many 
diseases. RDW was found to be an independent predictor of esophageal burn (Aydin et al., 2017). In parallel with the literature we found some inflammatory markers (WBC, LYM, PLT, RDW, MPV, NLR, PLR) values of the patients were statistically different, $(\mathrm{p}<0.05)$. But no statistically significant difference was found between the hospitalization and discharge NEU, PDW, PNR, PDW/RDW and CRP values of the patients, $(p>0.05)$. It can be related with our patients' number was smaller.

In studies conducted, routine esophagoscopy is still controversial in patients who have suspicious corrosive substance ingestion and who do not have any clinical symptoms. While some studies recommend routine esophagoscopy, some others recommend hospitalization and follow up (Gaudrealt et al., 1983; Previtera et al., 1990; Romanczuk and Ryszard, 1992; Nuutinen et al., 1994; Roy et al., 1995). In order to keep inflammation in minimum level in patients who have symptoms and who cannot have endoscopy, oral intake should be closed for 72 hours (Genc and Mutaf, 2002; Ozguner et al., 2002). In our study, endoscopy was performed on 2 patients who ingested drain cleaner and had burnt induced lesions around or inside the mouth, hypersalivation and edema on the lips. Both patients were not found to have sign of burn.

Keeping corrosive substances in high shelves and locked cupboards where children cannot reach, educating families by means of media or institutions, making the packages of corrosive substances in colors and shapes that won't attract children's attention, making locks on the lids that children cannot open, putting warnings for families, keeping these substances away from the children and pouring them away immediately after they are put in glasses or different containers during cleaning will significantly reduce this important health problem.

\section{Conclusion}

Although no complications resulting from corrosive substance ingestion occurred in our study, complications have a serious impact on the life quality of children and their families. Hemogram parameters can be an independent predictor of esophageal burn for this, more comprehensive studies should be done. It is a fact that diagnosis and treatment are still disputed and corrosive substance ingestion, which is mostly a problem in developing countries, can be prevented to a great extent with some simple precautions.
Ethics Committee Approval: Ethics committee approval was received for this study from Clinical Research Ethics Committee of Ordu University Medical Faculty (Date:07/02/2019, Number: 201923).

Peer-review: Externally peer-reviewed.

Author Contributions: Concept-OY, AA; Design-OY, AA; Supervision-OY, AA; FundingOY, AA; Materials-OY, AA; Data Collection/Data Processing-OY, AA; Analyze and İnterpretationOY, AA; Literature Review-OY, AA; Writing-OY, AA; Critical Review-OY, AA

Conflict of Interest: No conflict of interest was declared by the authors.

Financial Disclosure: The authors declared that this study hasn't received no financial support.

\section{References}

Aksu B, Inan M. Corrosive Burns of the Esophagus in Children. Medical Journal of Trakya University 2002;19:183-8.

Anderson KD, Rouse TM, Randolph JG. A controlled trial of corticosteroids in children with corrosive injury of the esophagus. N Engl J Med. 1990;323:637-40.

Ashcraft KW, Padula RT. The effect of dilute corrosives on the esophagus. Pediatrics. 1974;53(2):226-32.

Atabek C, Surer I, Demirbag S, Caliskan B, Ozturk $\mathrm{H}$, Cetinkursun S. Increasing tendency in caustic esophageal burns and long-term polytetrafluorethylene stenting in severe cases: 10 years experience. J Pediatr Surg. 2007;42(4):636-40.

Aydin E, Beser OF, Sazak S, Duras E. Role of RDW in Prediction of Burn after Caustic Substance Ingestion. Children (Basel). 2017;5(1):10.3390

Berthet B, Costanzo J, Arnaud C, Choux R, Assadourian R. Influence of epidermal growth factor and interferon $\mathrm{G}$ on healing of oesophageal burns in the rat. Br J Surg. 1994; 81:395-8.

Cankorkmaz L, Koyluoglu G, Guney C. Children with corrosive esophageal burns and esophagoscopy. Journal of Pediatric Surgery 2009;23(3):110-3.

Fulton JA, Hoffman RS. Steroids in second degree caustic burns of the esophagus: a systematic pooled analysis of fifty years of human data: 1956-2006. Clin Toxicol (Phila) 2007;45:402-8. 
Gaudreault P, Parent M, McGuigan MA, Chicoine L, Lovejoy FH Jr. Predictability of esophagealinjuryfromsignandsymptoms: study of causticingestion in 378 children. Pediatrics 1983;71:767-70.

Genc A, Mutaf O. Esophageal Motility Changes In Acute And Late Periods Of Caustic Esophageal Burns And Their Relation To Prognosis In Children. J Pediatr Surg. 2002;37:1526-28.

Hawkins DB, Demeter MJ, Barnett TE. Caustic ingestion: controversies in management: A review of 214 cases. Laryngoscope. 1980;90:98100.

Hugh T.B, Kelly M.D. Corrosive ingestion and the surgeon. J Am Coll Surg. 1999;189:508-22.

Jelenko C, 3rd, Story J, Ellison RG, Jr. Ingestion of mineral acid. Am Surg. 1974;40(2):97-104.

Kasap E, Ozutemiz A. Danger in pet bottle: Corrosive esophagitis. Current Gastroenterology 2006;10:29-35.

Kayaalp L, Odabası G, Dogangun B, Cavusoglu P, Bolat N, Bakan M, et al. Corrosive esophagitis in children: social and psychological aspects. Turk Pediatri Ars. 2006;41:24-30

Nicosia JF, Thornton JP, Folk FA, Saletta JD. Surgical management of corrosive gastric injuries. AnnSurg. 1974;180(2):139-43.

Nuutinen M, Uhari M, Karvali T, Kouvalainen K. Consequences of causticingestions in children. Acta Paediatr 1994;83:1200-5.

Oldham KT, Colombani PM, Foglia RP, Skinner MA (eds). Principles and practise of pediatric surgery. Philadelphia: Lippincott Williams \& Wilkins; 2005. 1023-39.

Ozguner IF, Savas C, Yavuz MS, Kaya SA, Buyukyavuz BI. The Accidental Caustic Esophagitis in Children. SDU Medical Faculty Journal. 2002;9(3).

Previtera C, Giusti F, Guglielmi M. Predictive value of visible lesions in suspected caustic ingestion: may endoscopy reasonably be omitted in completely negative pediatric patient? Pediatr Emerg Care. 1990; 6:176-178.

Rama BR, Robert SF. Caustics and Batteries. In Goldfrank's Toxicologic Emergencies, 4th Ed (Eds Goldfrank LR et al.): Connecticut, Appleton-Lange. 1998; 1399-1424.

Romanczuk W, Ryszard K. The significance of early panendoscopy in caustic ingestion in children. Turk J Pediatr. 1992; 34:93-98.

Roy CC, Silverman A, Alagille D. Esophageal burns and foreign bodies. Pediatric Clinical Gastroenterology. St Louis: Mosby Year Book Inc.; 1995:153- 158.
Sumeli R. The efficiency of Hypericum perforatum oily in treatment of corrosive esophageal. Trabzon: Karadeniz Technical University Faculty of Medicine, Medical specialty thesis. 2018.

Wasserman RL, Ginsburg CM. Caustic substanse injuries. J Pediatr. 1985; 107:169-174. 